Conclusion A RNS shoulder injection clinic works well but the range of possible diagnoses requires close collaboration with the Rheumatologist.

\section{Bone and joint decade}

\section{SP0154 THE BJD: EXPERIENCES FROM SWEDEN AND (SOMEWHAT) FROM THE NORDIC COUNTRIES}

LM Oehrsvik. Chair, The Swedish Rheumatism Association, Stockholm, Sweden

10.1136/annrheumdis-2001.1284

The work with the Bone and Joint Decade is well underway in many countries by now. In Sweden the practical work is led by a small 5 person steering group and as a complement to this there is a foundation used to gather funds for the project. There is also a larger reference group whose opinions and ideas are tapped every once in a while. In this group there are representatives from the rheumatologists as well as orthopaedics, other health professionals but also patients.

In this short summary the activities undertaken on part of the Bone and Jone Decade in Sweden will not be listed. Our intention is to cease every opportunity to spread the message, different conferences for doctors and health professionals, and in the patient societies but it also gives us a good opportunity to spread information through the media and directly to decision makers at different levels.

The main benefits of the work with the decade are the following: It increases co-operation between the patients and doctors and all the health professionals. The decade also puts focus on the need for more co-operation between the different disciplines within medicine, which is of great importance.

In order to lessen the suffering and bring down the costs for the individual as well as societies we must spread information and influence politicians.

In the other Nordic countries the work has been organised in a somewhat different manner and as the chair of the Nordic Rheuma Council (www.nrr.nu) I will take the liberty of giving some examples from the other Nordic countries in the cases where they are not speaking of this themselves.

At a purely Nordic level the Nordic Rheuma Council has been active and has managed to get the Committee for Nordic Affairs inside the Nordic Council, a body made up of Nordic parliamentarians, to urge the Nordic governments to all sign the declaration of the Bone and Joint Decade.

\section{Osteo-arthritis}

\section{HP0010 LONG-TERM EFFECTS OF NONSTEROIDAL ANTINFLAMMATORY DRUGS ON HUMAN CHONDROCYTES IN ALGINATE BEADS}

C Sanchez, M Deberg, J-Y Reginster, Y Henrotin. Bone and Cartilage Metabolism Research Unit, University Hospital, Sart-Tilman, 4000 Liège, Belgium

10.1136/annrheumdis-2001.1285

This study was designed to compare the long-term effects (12 days) of nonsteroidal anti-inflammatory drugs (NSAID) on the metabolism of human chondrocytes cultured in alginate beads.
Enzymatically isolated osteoarthritic (OA) chondrocytes were cultured in alginate beads in a well-defined culture medium (DMEM + ITS+) for 12 days. Interleukin-6 and -8 (IL-6, IL-8), stromelysin (MMP-3) and aggrecan (AGG) productions were assayed by specific enzyme amplified sensitivity immunoassays (EASIA), and prostaglandin E2 (PGE2) production by a specific radioimmunoassay. All NSAID were tested at the mean peak plasmatic concentration (Cmax) obtained after oral administration of a therapeutic dose. The Cmax used in this study were $7.5 \mathrm{mg} / \mathrm{ml}$ for aceclofenac (ACECLO), $1.4 \mathrm{mg} / \mathrm{ml}$ for diclofenac (DICLO), $2 \mathrm{mg} / \mathrm{ml}$ for indomethacin (INDO), $3 \mathrm{mg} / \mathrm{ml}$ for nimesulide (NIM), $1 \mathrm{mg} / \mathrm{ml}$ for rofecocib (ROFE), $0.7 \mathrm{mg} / \mathrm{ml}$ for celecoxib (CELE), $7 \mathrm{mg} / \mathrm{ml}$ for piroxicam (PIROX), and $25 \mathrm{mg} / \mathrm{ml}$ for ibuprofen (IBUP).

At the therapeutic concentration, all NSAID tested fully blocked PGE2 production. Interestingly, ACECLO, DICLO, INDO, NIM and IBUP significantly inhibited both basal and IL1b-stimulated IL-6 production, whereas ROFE, CELE and PIROX had no significant effects. No NSAID showed significant effects on basal and IL-1b-stimulated IL- 8 production, excepted CELE and IBUP which slightly increased basal IL-8 production. ACECLO and INDO increased by $25 \%$ AGG content in the alginate beads, while the other NSAID were without significant effect. Furthermore, none NSAID were able to modify the inhibitory effect of IL-1b on AGG production. Finally, NSAID did not modify MMP-3 production.

From this study, we can conclude that the mechanism of action of NSAID seems to be multifactorial and not limited to the inhibition of cyclooxygenases. Furthermore, in our culture conditions, at the Cmax and by comparison with other NSAID ACECLO and INDO show a advantageous profile of activity. They fully block PGE2 production, inhibit IL-6 synthesis and increase aggrecan synthesis. These effects would appear to be advantageous for the long-term treatment of chronic joint diseases such as osteoarthritis.

\section{HP0011 WHAT IS THE DEMAND FOR OSTEOARTHRITIS SELF- MANAGEMENT EDUCATION?}

MM Rooney, DV Doyle, C Tierney, M Greenwood. Rheumatology, Whipps Cross Hospital, London, UK

\subsection{6/annrheumdis-2001.1286}

Background People with arthritis in the UK can obtain significant health benefits from attendance at a lay-led arthritis self management programme. ${ }^{1}$ We have found significant improvements in knowledge relevant to self-management following attendance at a nurse-led community-based osteoarthitis (OA) education programme and an $82 \%$ reduction in OA-related visits to the GP in the 12 months following. ${ }^{2}$ It was envisaged that there could be substantial benefits to quality of care and savings in terms of healthcare resources if in future GPs were to have the option of referring patients with OA-related problems to such a programme run regularly within their own surgery by their practice nurse. Potentially demand could be high. Over the period of one year, 25\% of UK and Netherlands over 55 year olds are reported to have experienced persistent knee pain prompting one in six to have consulted their GP. ${ }^{3}$

Aim To evaluate the feasibility of implementing such a scheme in general practice and to assess the uptake of the course by both GPs and their patients. 